\title{
Relationship of Hypocalciamia and Severity of Disease in COVID-19 Patients in Lahore Pakistan
}

\author{
Hamid Mahmood", ", Talmeez Zaib Shah², Sohail Rasool ${ }^{3}$, Ammara Waqar ${ }^{4}$, \\ Muhammad Zia-ul-Miraj ${ }^{5}$, Awais Gohar ${ }^{6}$, Abdul Rauf ${ }^{7}$ \\ ${ }^{1}$ Department of Bio-Chemistry, Federal Medical and Dental College, Islamabad, Pakistan \\ ${ }^{2}$ Department of Bio-Chemistry, Amna Anyat Medical College, Lahore, Pakistan \\ ${ }^{3}$ Forensic Medicine Department, Al-Aleem Medical College, Lahore, Pakistan \\ ${ }^{4}$ Quality Enhancement Cell, Al-Aleem Medical College, Lahore, Pakistan \\ ${ }^{5}$ Department of Medical Education, Al-Aleem Medical College, Lahore, Pakistan \\ ${ }^{6}$ Primary and Secondary Health Department, Government of the Punjab, Lahore, Pakistan \\ ${ }^{7}$ Department of Medicine, Al-Aleem Medical College, Lahore, Pakistan
}

\section{Email address:}

drhamidmahmood373@gmail.com (H. Mahmood), tzshah95@gmail.com (T. Z. Shah), sxrasool@irishprisons.ie (S. Rasool), ammarahamid24@gmail.com (A. Waqar), z_u_miraj@yahoo.com (M. Zia-ul-Miraj),dr.awais.gohar@gmail.com (A. Gohar), Abrauf247@gmail.com (A. Rauf)

*Corresponding author

\section{To cite this article:}

Hamid Mahmood, Talmeez Zaib Shah, Sohail Rasool, Ammara Waqar, Muhammad Zia-ul-Miraj, Awais Gohar, Abdul Rauf. Relationship of Hypocalciamia and Severity of Disease in COVID-19 Patients in Lahore Pakistan. American Journal of Biomedical and Life Sciences. Vol. 9, No. 1, 2021, pp. 36-42. doi: 10.11648/j.ajbls.20210901.15

Received: November 18, 2020; Accepted: December 7, 2020; Published: January 22, 2021

\begin{abstract}
Introduction: In Pakistan, a wave of coronavirus has started in February which was first reported in Wahun City China. Abnormal calcium blood level is considered one of the important and common electrolyte disturbances in patients with severe infection. The effect of blood calcium level on the severity of COVID-19 and the possible immune regulation mechanism is considered to be an important factor related to severity of disease. Aim of the Study: To find out the correlation of blood calcium levels and related risk factors of patients suffering from COVID-19 and provide a basis for early intervention in patients with relevant clinical characteristics and further reduce the incidence of critical illness and mortality in COVID-19 patients. Method: 180 COVID-19 patients were admitted to Gulab Devi Teaching Hospital, Lahore between February to July 2020. Subject index were tested on real-time fluorescent RT-PCR test. On the basis of the result of RT-PCR, they were divided into two groups according to clinical symptoms as mild (control/placebo group) and critical (experimental group). The patient with the mild symptom were included in the placebo group, whereas patient with the severe symptoms were included in the experimental group. Exclusion criteria: The patients who do not show the detection level of viral infection with the RT-PCR are excluded from the study. Results: The comparison has been carried out between the placebo group and the experimental group on the basis of various parameters. The patients serum calcium level was tested and the value for hypocalcemia was declared as per universal recommendation which is $<2.13 \mathrm{mmol} / \mathrm{L}$. According to the corrected serum total calcium level, COVID-19 patients can be divided into hypocalcemia group and normal blood calcium group. The result showed that hypocalcemia and immune dysfunction was found high in experimental group as compare to control group which shows a strong correlation between hypocalcemia and COVID-19 disease. Conclusion: It has been concluded from the study that patients with COVID-19 have obvious hypocalcemia and immune dysfunction, especially in experimental group patients. In this study, it is easy to be combined with multiple infections caused by pathogenic bacteria under certain conditions. Close monitoring of blood calcium levels can predict the severity of the disease more effectively.
\end{abstract}

Keywords: Hypocalcemia, COVID-19, Severity of Disease, RT-PCR, Viral Infection, Blood Calcium Level 


\section{Introduction}

In Pakistan, a wave of coronavirus has started in February that was first reported in Wahun City China. This wave continues to spread coronavirus that has never been detected in humans or animals, called COVID-19 [1]. The World Health Organization (WHO) declared COVID-19 as a pandemic disease which showed reaction of different degrees resulting in severity of symptoms in patients. As of July 31, 2020, a total of 2,79,146 people have been diagnosed in Pakistan, and a total of 5,970 people have died which is in comparison to the Hubei province of China was quite few [2, $3]$. Total numbers of death are less as compare to the Wahun city of China [4].

A study has been carried out regarding the prevalence of hypocalcemia in the patients admitted with COVID-19 infection. It has been found out that the hypocalcemia was present in most of the hospitalized patients with COVID-19 disease [5]. Another study has been carried out about the hypocalcemia in the patients suffering with COVID-19 disease. It was found out that the hypocalcemia is an important feature found in the COVID-19 patients [6].

Another study has been carried out to find out mechanistic basis and therapeutic relevance of hypocalcemia during severe COVID-19 infection. The result of the study showed that the hypocalcemia was found to be important clinical indicator with reference to severity of disease in the COVID19 patients [7]. Therefore, it is extremely important to accurately and effectively judge the severity and prognosis of COVID-19 infection. Abnormal calcium metabolism is one of the important and common electrolyte disturbances in patients with severe infection, the effect of blood calcium level on the severity of COVID-19 and the possible immune regulation mechanism is yet to be determined [8].

\section{Background}

Corona virus is a new pandemic disease which has detected the persons globally. Recently all the countries have started research and try to share their research with all the countries in order to save the precious lives globally. The relationship between the electrolyte balance and severity of the disease in COVID-19 infected patients has gain importance in terms of its clinical importance.

Guan et al. carried out a research to find out the clinical characteristics of patients suffering from COVID-19. He concluded that the level of calcium and other electrolytes played an important role in carrying out immunological functions in the world. He was of the opinion that the clinical characteristics of the patients must be properly and regularly being monitor in order to find out their proper relevance to the disease [9].

Millet and Whittaker carried out a research on the SARS$\mathrm{CoV}$ patients in order to find out the relationship of calcium ion concentration and its physiological and molecular triggers membrane fusion and entry into host cells. He found out that the concentration of the calcium ion plays an important role for the transportation across the membrane in to host cell as the similarity between the SARS virus and the corona virus is similar. So the detailed study is needed to find out calcium ion concentration to the severity of the disease [10].

Straus et al. carried out a research on concentration of calcium ions in corona virus patients. He found out that $\mathrm{Ca} 2+$ ions promote fusion of Middle East respiratory syndrome coronavirus with host cells and increase infectivity. His research concluded that the constriction of calcium ions play an important role in the immune response by the body [11].

Nathan et al. carried out a research on the calcium ions and its relation to Ebola virus fusion peptide and its relationship to infection in infected persons. His study concluded that calcium ions interact with Ebola virus fusion peptide that promotes structure-function changes in the infected persons [12].

Bossoni et al. carried out a study to find out the relationship of hypocalcemia with other comorbid conditions suffering from COVID-19. His study concluded that severe hypocalcemia in a thyroidectomized woman with Covid-19 infection has increase the severity of the disease suffering from corona virus [13].

\section{Aim of the Study}

To find out the correlation between blood calcium levels and related risk factors of patients suffering from COVID-19 and provide a basis for early intervention in patients with relevant clinical characteristics and further reduce the incidence of critical illness and mortality.

\section{Methods and Material}

Study Type: Retrospective Study

Settings: This study has been conducted in Gulab Devi Teaching Hospital, Lahore, Pakistan.

Duration of Study: Six Months from February 2020 to July 2020

Sampling Technique: The data has been collected from the subject index coming to the Quarantine Center, CCU and ICU Gulab Devi Teaching Hospital, Lahore, Pakistan through random number table method which were further divided into experimental group and the control group.

\section{Sample Selection}

Inclusion Criteria: All persons coming to the Quarantine Center, CCU and ICU Gulab Devi Teaching Hospital, Lahore, Pakistan.

Exclusion Criteria: All persons coming to the Quarantine Center, CCU and ICU Gulab Devi Teaching Hospital, Lahore, Pakistan who were confirmed through RT-PCR technique but not suffering from the COVID-19

Study Tools: Questionnaire and Interview

Sample size $(\mathrm{n})=180 \quad$ (Control/placebo Group=140, Experimental Group $=40 ; 90$ males and 90 females) 


\subsection{Methodology}

The patients which were tested positive by the RT-PCR were divided into control and experimental group. The selected patients who met the diagnostic criteria of COVID-19 as proposed by Chinese Health Commission was adopted [14]. The following signs and symptoms were recorded to find out the improvement in the different levels before and after the therapy in the control and experimental group. Following parameters were tested and compared between the controlled and experimental group:

1) blood routine,

2) inflammation indicators

3) C-reactive protein (CRP),

4) various biochemical indicators,

5) alanine aminotransferase (ALT),

6) aspartate aminotransferase (AST),

7) alkaline phosphatase (Alkaline phosphatase (ALP),

8) blood phosphorus (phosphorus, P),

9) blood calcium,

10) ALB, the percentage of $T$ lymphocyte subsets (CD4 $\mathrm{T}$ cells, $\mathrm{CD} 8^{+} \mathrm{T}$ cells $)$

11) cytokines

12) interleukin 4 (IL- 4) Interleukin 17 (IL-17), interferon $\gamma(\mathrm{IFN}-\gamma)$

13) glomerular filtration rate (eGFR) by the dietary improvement experimental formula for kidney disease,

14) $\mathrm{EGFR}=186 \mathrm{x}[\text { blood creatinine } \mathrm{x} 0.011]^{-1.154} \mathrm{x}$ [age $^{-0.203}$ $\mathrm{x} 0.742$ (female) x1.233

The correction formula for serum total calalbumin is: corrected blood calcium value $(\mathrm{mmol} / \mathrm{L})=$ measured calcium value $(\mathrm{mmol} / \mathrm{L})-0.02 \mathrm{x}$ [measured value of serum albumin (ALB) $\mathrm{g} / \mathrm{L}-40]$.

\subsection{Data Analysis}

Data has been collected in the MS Excel sheet which was exported to SPSS 26.0 for analysis. For the purpose of analysis of normal distribution, mean and standard deviation was calculated. For non-normal distribution, the median and interquartile range was calculated, $t$ test was performed in order to compare between the groups. For the experimental group Multivariate Logistic regression analysis was performed $P<0.05$ was considered as the difference which taken as significant.

\section{Results}

\subsection{Comparison of Various Indicators Between the Experimental Group and the Placebo Group}

There were 40 cases in the experimental group, with an average age of $60.91 \pm 18.02$ years old, and males accounted for $52.5 \%$. The patients serum calcium level was tested and the value for hypocalcemia was declared as per universal recommendation which is $<2.13 \mathrm{mmol} / \mathrm{L}$ [15]. Among them, 10 cases of hypertension (accounting for 25\%), 17 cases of diabetes (accounting for 42.5\%), 9 cases of basic respiratory disease (accounting for 22.5\%), 11 cases of cardiovascular disease (accounting for 27.5\%); placebo group 140 cases, The average age is $45.23 \pm 15.14$ years old, and males account for $49.28 \%$. Among them, 21 cases of hypertension (accounting for 15\%), 10 cases of diabetes (accounting for $7.2 \%$ ), 5 cases of basic respiratory disease (accounting for $3.6 \%$ ), and 7 cases of cardiovascular disease (accounting for $5 \%$ ); compared with the placebo group, CRP, FPG, IFN- $\gamma$, IL-17 levels are elevated, the percentage of lymphocytes, ALB, corrected blood calcium, CD4 ${ }^{+} \mathrm{T}$ Cell $\%$ and CD ${ }^{+} \mathrm{T}$ cell\% levels decreased and the difference was statistically significant $(P<0.05)$; the two groups had no composition of gender, proportion of hypertension, ALT, eGFR, CD4 ${ }^{+} / \mathrm{CD} 8$ ${ }^{+}$ratio, and IL-4 level significant difference, $(P>0.05)$ (see table 1).

Table 1. Comparison of various indicators between the experimental group and the placebo group.

\begin{tabular}{|c|c|c|c|}
\hline index & Experimental group $[\bar{x} \pm$ s/cases $(\%)]$ & Placebo group $[\bar{x} \pm \mathbf{s} /$ number of cases $(\%)]$ & Pvalue \\
\hline Number of cases (n) & $40(22.22)$ & $140(77.78)$ & \\
\hline Age & $60.91 \pm 18.02$ & $45.32 \pm 15.14$ & $0.001 *$ \\
\hline Male n $(\%)$ & $21(52.5)$ & $69(49.28)$ & 0.832 \\
\hline High blood pressure & $10(25)$ & $21(15)$ & 0.303 \\
\hline Diabetes & $17(42.5)$ & $10(7.2)$ & $0.001 *$ \\
\hline Underlying respiratory disease & $9(22.5)$ & $5(3.6)$ & $0.001 *$ \\
\hline Cardiovascular diseases & $11(27.5)$ & $7(4.5)$ & $0.001 *$ \\
\hline C-reactive protein $(\mathrm{mg} / \mathrm{L})$ & $28.1(7.85,93.75)$ & $9.07(2.98,22.03)$ & $0.003^{*}$ \\
\hline Percentage of lymphocytes (\%) & $27.13 \pm 11.99$ & $16.97 \pm 9.10$ & $0.001 *$ \\
\hline Fasting blood glucose $(\mathrm{mmol} / \mathrm{L})$ & $8.01 \pm 3.52$ & $5.99 \pm 2.01$ & $0.005^{*}$ \\
\hline $\operatorname{ALT}(\mathrm{U} / \mathrm{L})$ & $45.21 \pm 12.03$ & $33.96 \pm 9.93$ & 0.100 \\
\hline eGFR (ml. min-1. (1.73m2)-1) & $106.98 \pm 22.97$ & $109.89 \pm 19.17$ & 0.380 \\
\hline Corrected blood calcium $(\mathrm{mmol} / \mathrm{L})$ & $2.11 \pm 0.17$ & $2.30 \pm 0.22$ & $0.001 *$ \\
\hline CD4+T cells $(\%)$ & $45.71 \pm 11.03$ & $52.02 \pm 14.21$ & $0.002 *$ \\
\hline CD8+T cells $(\%)$ & $22.22 \pm 11.04$ & $34.13 \pm 8.99$ & $0.001 *$ \\
\hline $\mathrm{IL}-4(\mathrm{pg} / \mathrm{mL})$ & $1.10 \pm 0.43$ & $0.90 \pm 0.30$ & 0.353 \\
\hline $\mathrm{IFN}-\gamma(\mathrm{pg} / \mathrm{mL})$ & $3.13 \pm 0.61$ & $1.52 \pm 0.29$ & $0.028 *$ \\
\hline $\mathrm{IL}-17(\mathrm{pg} / \mathrm{mL})$ & $1.82 \pm 0.53$ & $1.31 \pm 0.62$ & $0.041 *$ \\
\hline
\end{tabular}

Note: $1 \mathrm{mmHg}=0.133 \mathrm{kPa}$; ALT: alanine aminotransferase; eGFR: estimated glomerular filtration rate; IL-4: interleukin 4; IFN- $\gamma$; interferon $\gamma$; IL-17: interleukin $17 ; * \mathrm{P}<0.05$. 


\subsection{Analysis of Influencing Factors in Experimental Group}

In the experimental group, the dependent variable and the adjusted blood calcium level, age, gender, presence or absence of comorbidities, SBP, CRP, FPG, ALT, eGFR, CD4
${ }^{+} \mathrm{T}$ cell $\%, \mathrm{CD} 8{ }^{+} \mathrm{T}$ cell $\%$ as independent variables, multifactor Logistic regression analysis has been done after adjusting for decreased blood calcium levels, age and eGFR increased risk factors for patients suffering from severe COVID-19 (see table 2).

Table 2. Logistic regression analysis of influencing factors in experimental group.

\begin{tabular}{llll}
\hline Variable & $\boldsymbol{\beta}$ value & Standard error & P value \\
\hline Constant & 19.674 & 16.031 & 0.216 \\
Corrected blood calcium (mmol/L) & 23.321 & 8.213 & $0.004^{*}$ \\
Age & 0.201 & 0.089 & $0.031^{*}$ \\
Gender & 1.702 & 1.763 & 0.335 \\
With or without complications & 1.212 & 1.929 & 0.534 \\
Systolic blood pressure (mmHg) & 0.011 & 0.045 & 0.789 \\
C reactive protein (mg/L) & 0.012 & 0.019 & 0.535 \\
Percentage of lymphocytes (\%) & 0.046 & 0.098 & 0.630 \\
Fasting blood glucose (mmol/L) & 0.559 & 0.389 & 0.149 \\
ALT (U/L) & 0.074 & 0.048 & 0.107 \\
eGFR (ml-min-1 $\cdot(1.73 \mathrm{~m} 2)-1)$ & 0.166 & 0.082 & $0.044^{*}$ \\
CD4+T cells (\%) & 0.081 & 0.070 & 0.234 \\
CD8+T cells (\%) & 0.151 & 0.109 & 0.169 \\
\hline
\end{tabular}

Note: ALT: alanine aminotransferase; eGFR: estimated glomerular filtration rate; $* \mathrm{P}<0.05$.

\subsection{Comparison of Various Indexes Between Low Calcium Group and Normal Calcium Group}

When the patient was admitted to the hospital without treatment, the serum total calcium level before correction was $(2.12 \pm 0.23) \mathrm{mmol} / \mathrm{L}$, and the serum total calcium level after serum albumin correction was $(2.18 \pm 0.19) \mathrm{mmol} / \mathrm{L}$. Among them, 61 patients with low calcium, accounting for $37.22 \%$. In order to analyze the causes of low calcium, compared with the normal calcium group, the low calcium group has lower levels of serum albumin, CD4 ${ }^{+} \mathrm{T}$ cell $\%$, CD8 ${ }^{+} \mathrm{T}$ cell $\%$, age, the proportion of experimental group patients, combined diabetes, respiratory diseases and cardiovascular diseases ratio, CRP levels, the difference was statistically significant $(P<0.05)$. Biochemical parameters were not statistically different $(P>0.05)$ (see table 3$)$.

Table 3. Comparison of various indexes between low calcium group and normal calcium group.

\begin{tabular}{|c|c|c|c|}
\hline index & $\begin{array}{l}\text { Low calcium group }[\bar{x} \pm \text { s/number of } \\
\text { cases }(\%)]\end{array}$ & $\begin{array}{l}\text { Normal calcium group }[\bar{x} \pm \text { s/number of } \\
\text { cases }(\%)]\end{array}$ & Pvalue \\
\hline Number of cases (n) & $67(37.22)$ & $113(62.78)$ & \\
\hline Age & $53.45 \pm 19.72$ & $44.01 \pm 16.22$ & $0.001 *$ \\
\hline Male n $(\%)$ & $36(53.73)$ & $59(52.21)$ & 0.543 \\
\hline Critical illness n (\%) & $29(43.3)$ & $8(7.08)$ & $0.001 *$ \\
\hline \multicolumn{4}{|l|}{ Complications } \\
\hline High blood pressure & $12(17.9)$ & $19(16.8)$ & 0.527 \\
\hline diabetes & $13(19.4)$ & $12(10.6)$ & $0.043 *$ \\
\hline Underlying respiratory disease & $9(13.4)$ & $5(4.4)$ & $0.042 *$ \\
\hline Cardiovascular diseases & $11(16.4)$ & $6(5.3)$ & $0.007 *$ \\
\hline C-reactive protein $(\mathrm{mg} / \mathrm{L})$ & $12.99(4.98,48.01)$ & $9.15(2.32,24.97)$ & $0.042 *$ \\
\hline Percentage of lymphocytes (\%) & $23.18 \pm 11.99$ & $26.03 \pm 13.01$ & 0.234 \\
\hline Blood calcium before correction $(\mathrm{mmol} / \mathrm{L})$ & $1.89 \pm 0.21$ & $2.19 \pm 0.15$ & $0.001 *$ \\
\hline Corrected blood calcium $(\mathrm{mmol} / \mathrm{L})$ & $2.01 \pm 0.17$ & $2.32 \pm 0.15$ & $0.001 *$ \\
\hline Blood phosphorus (mmol/L) & $1.09 \pm 0.29$ & $1.19 \pm 0.21$ & 0.297 \\
\hline Alkaline Phosphatase (U/L) & $61.03 \pm 16.98$ & $62.12 \pm 16.13$ & 0.933 \\
\hline $\operatorname{ALT}(\mathrm{U} / \mathrm{L})$ & $43.12 \pm 17.01$ & $34.96 \pm 8.19$ & 0.380 \\
\hline $\operatorname{AST}(\mathrm{U} / \mathrm{L})$ & $44.98 \pm 13.97$ & $30.95 \pm 4.90$ & 0.107 \\
\hline eGFR $(\mathrm{ml} \bullet \mathrm{min}-1 \bullet(1.73 \mathrm{~m} 2)-1)$ & $109.02 \pm 19.14$ & $113.02 \pm 13.97$ & 0.543 \\
\hline Serum albumin $(\mathrm{mmol} / \mathrm{L})$ & $33.96 \pm 5.38$ & $43.32 \pm 3.46$ & $0.001 *$ \\
\hline CD4+T cells $(\%)$ & $46.03 \pm 13.34$ & $53.16 \pm 13.14$ & $0.01 *$ \\
\hline CD8+T cells $(\%)$ & $26.32 \pm 9.89$ & $33.12 \pm 10.08$ & $0.001 *$ \\
\hline $\mathrm{CD} 4+/ \mathrm{CD} 8+$ ratio & $2.09 \pm 1.91$ & $1.69 \pm 0.79$ & 0.129 \\
\hline $\mathrm{IL}-4(\mathrm{pg} / \mathrm{mL})$ & $1.51 \pm 0.49$ & $1.53 \pm 0.50$ & 0.265 \\
\hline IFN- $\gamma(\mathrm{pg} / \mathrm{mL})$ & $2.90 \pm 0.71$ & $2.09 \pm 0.56$ & 0.446 \\
\hline IL-17 (pg/mL) & $2.72 \pm 0.48$ & $2.19 \pm 0.43$ & 0.275 \\
\hline
\end{tabular}

Note: ALT: alanine aminotransferase; AST: aspartate aminotransferase; eGFR: estimated glomerular filtration rate; IL-4: interleukin 4; IFN- $\gamma$; interferon $\gamma$; IL17: Interleukin $17 ; * \mathrm{P}<0.05$ 


\section{Discussion}

COVID-19 is a lung inflammation caused by a new type of coronavirus. It is highly contagious and changes rapidly. Severe cases can cause breathing difficulties, organ dysfunction, and even death. With a global outbreak, its high pathogenicity and the mortality rate has attracted worldwide attention. For the purpose of COVID-19 patient diagnosis, we are currently using indicators to assess the condition and prognosis of patients such as: CRP, procalcitonin (Procalcitonin, PCT), white blood cell count, etc. that have advantages and disadvantages of diagnosis, so more indicators are needed to comprehensively evaluate the prognosis of the disease.

Calcium in the body not only constitutes teeth and bones, but also participates in neurotransmitter release, hormone secretion, maintenance of blood coagulation and internal environment stability. The vast majority of blood calcium exists in plasma, including diffuse calcium and non-diffuse calcium. The former is mainly physiologically active The latter can be combined with plasma albumin, accounting for $40 \%-50 \%$ of the total, and the two can be converted to each other to achieve dynamic balance.

Booth et al. conducted a retrospective multicenter study of 144 patients with severe acute respiratory syndrome (SARS) in the Toronto area, the incidence of hypocalcemia is as high as $60 \%$ [16]. Comprehensive clinical and laboratory characteristics can help improve disease diagnosis and poor prognosis analysis capabilities.

Qing et al carried out a study of 25 untreated SARS patients showed that hypocalcemia was found in the experimental group in great numbers [17].

Our study was a retrospective study. This study included 180 patients with COVID-19 in Gulab Devi Teaching Hospital, Lahore. Among them, $37.22 \%$ of them had lowered blood calcium levels, and the blood calcium level was significantly negatively correlated with the severity of the disease, indicating that hypocalcemia is more common in COVID-19 patients, which is partly consistent with previous studies on other types of coronavirus infections in China and USA and may be related to differences in the degree and types of diseases included in this study [18].

Due to the relatively insidious manifestations of hypocalcemia, clinical work is often ignored [19]. Therefore, hypocalcemia as the basis of infection in COVID-19 patients or the clinical manifestations after infection is still inconclusive.

Early effective evaluation of the clinical and laboratory characteristics of experimental group patients as compare to control group with proper intervention can effectively reduce the incidence of severity of disease in the experimental group patients.

Compared with the placebo group and experimental group suffering from COVID-19, the proportion of diabetes, underlying respiratory disease and cardiovascular disease and the level of FPG were found significantly higher. Age and eGFR independent of other influencing factors can effectively predict the severity of COVID-19, suggesting that elderly patients are often accompanied by a decline in glomerular filtration function hence are more susceptible to the coronavirus, and are more likely to worsen after onset. Gender differences such as female $\mathrm{X}$ chromosome and sex hormone levels may reduce the protective effect of virus susceptibility [20]. It is not reflected in this study, and it is considered that it has caused by regional differences and limited sample size.

Studies have shown that both total calcium and adjusted calcium ion concentrations in ICU experimental group patients can assess disease severity to a certain extent [21]. To further analyze the causes of hypocalcemia in COVID-19 patients, the specific analysis is as follows:

1. We use the corrected total calcium level as the observation index. As the age increases, the proportion of chronic comorbidities increases and patients with low calcium are more likely to suffer from COVID-19. The higher the CRP level, the more is severity of disease. Severe stress or increased consumption, decreased synthesis and absorption and increased capillary permeability, the loss of albumin will increase, leading to calcium binding protein and non-diffusible calcium levels decrease, resulting in hypocalcemia. Because of low calcium, it is unable to perform normal physiological functions and there are serious complications such as the cardiovascular system [22]. Giustina and Formenti carried out a research on the relationship of hypocalcemia and its impact on the preventing a covid-19 disease in Italy. The result of his find were found in consistence with our study [23].

2. The level of liver ALT enzyme increased and the level of eGFR reflecting glomerular function decreased. Although the difference is not statistically significant, it still suggests a certain degree of liver and kidney damage, which may lead to decreased liver and kidney hydroxylase activity and activity of hydroxyvitamin D3 $(1,25(\mathrm{OH}) 2 \mathrm{D} 3)$. Hypocalcemia occurs due to insufficient synthesis of hydroxyvitamin D3 $(1,25$ $(\mathrm{OH}) 2 \mathrm{D} 3)$. Thomas et al. carried out a research and found of the impairment of renewal function in COVID-19 patients. The finding of his study was found to be in consistent with our present study [24].

3 . The disease broke out in winter and spring. People's outdoor activities and UV exposure time were relatively reduced, and vitamin $\mathrm{D}$ synthesis in the body decreased, resulting in insufficient $1,25(\mathrm{OH}) 2 \mathrm{D} 3$ synthetic substrates and induced hypocalcemia. This is similar to the results of a recent study published on medRxiv. The study found that it may be related to latitude and longitude, light, skin pigment, and eating habits [25].

4. This study found that there was a certain degree of decline in the level of $\mathrm{T}$ lymphocyte subsets in the low calcium group, suggesting that there may be a certain correlation between the decline in immune function and the deficiency of trace elements, but the specific mechanism is not yet clear [26]. 
$\mathrm{T}$ lymphocytes and their subgroups play an extremely important role in maintaining immune function. According to function and molecular phenotype, $\mathrm{T}$ lymphocytes can be divided into $\mathrm{CD} 4{ }^{+} \mathrm{T}$ cells and $\mathrm{CD} 8{ }^{+} \mathrm{T}$ cells. The former are mainly differentiated into Th1, Th2, Th17 and Regulatory T cells (regulatory $\mathrm{T}$ cells, Treg) four types of helper $\mathrm{T}$ cells, through the synthesis and secretion of cytokines to assist and regulate the immune response. Among them, Th1 cells secrete pro-inflammatory response factors mainly IFN- $\gamma$, Th2 cells secrete anti-inflammatory cytokines mainly IL-4 and pro-inflammatory cytokines mainly IL-17 secreted by Th17 cells. We have observed decreased levels of lymphocytes, CD4+ T cells, and CD8+ T cells in COVID-19 patients and increased levels of CRP, IFN- $\gamma$, and IL-17 factors, suggesting that in the acute phase of infection in experimental group patients with COVID-19. It cannot be ruled out that the coronavirus replicates in lymphocytes in large numbers or even directly destroys lymphocytes, causing continuous responses of cytokines and chemokines. Th1 and Th17 proinflammatory helper $\mathrm{T}$ cell subsets may be the main functional groups involved in immune disorders, and then increased inflammation, produce a "cytokine storm", resulting in deterioration of the degree of tissue damage. The results were similar to SARS moderate respiratory syndrome (Middle East respiratory syndrome, MERS) part [27, 28].

The mechanism of hypocalcemia in experimental group patients has not been fully elucidated. Some scholars believe that some cytokines and adhesion molecules may affect cell membrane permeability and calcium pump opening, leading to abnormal calcium ion transport inside and outside the cell [29]. As an important metabolite that regulates calcium and phosphorus metabolism, 1,25 $(\mathrm{OH}) 2 \mathrm{D} 3$ can also inhibit the production of Th1 and Th17 factors in the body, and has a certain immunomodulatory effect on $\mathrm{T}$ cell-mediated autoimmune diseases and sequelae of cerebral infarction [30]. Therefore, COVID-19 experimental group patients with hypocalcemia may also be widespread due to the lack of immunosuppression of active vitamin D and further research is urgently needed.

\section{Conclusion}

It has been concluded from the study that the blood calcium level is an important parameter to check the severity of the disease in COVID-19 patients. It has been found out that the monitoring of blood calcium levels can provide us about the severity of disease in the COVID-19 patients. The patients serum calcium level are hypocalcemia as per universal recommendation is $<2.13 \mathrm{mmol} / \mathrm{L}$. On the basis of this serum calcium level the deficiency of serum calcium level as shown sever impact on the progression of the disease. It is therefore concluded that the hypocalcemia and immune dysfunctions are correlated in COVID-19 disease. The patients with COVID-19 have obvious hypocalcemia and immune dysfunction, especially in experimental group patients. In this study, it is easy to be combined with multiple infections caused by pathogenic bacteria under certain conditions. Close monitoring of blood calcium levels can predict the severity of the disease more effectively.

\section{Limitation}

This study has been carried on a very limited scale in the city of Lahore which has included only one quarantine center in a teaching hospital of Lahore. More studies with large number of subject index should be conducted in order to find out more reliable and generalized results.

\section{Conflict of Interest}

All authors declare that there is no conflict of interest.

\section{References}

[1] Huang C, Wang Y, Li X, Ren L, Zhao J, Hu Y. et al. Clinical features of patients infected with 2019 novel coronavirus in Wuhan, China. Lancet. 2020. 395 (10223): 497-506. DOI: 10.1016/S0140-6736(20)30183-5.

[2] UNHCR. Pakistan: COVID-19 external update, July 2020. Situation Report. 7 Aug 2020. Available at https://reliefweb.int/report/pakistan/pakistan-covid-19external-update-july-2020.

[3] The official website of the National Health Commission. The latest situation of the new coronavirus pneumonia epidemic as of 24:00 on July $31^{\text {st }} \quad(2020-07-31)$ nhc.gov.cn/xcs/yqtb/202005/874765e641254eb4acea9d5e945f 4e01.shtml.

[4] Wang Y, Wang Y, Chen Y, Qin Q. Unique epidemiological and clinical features of the emerging 2019 novel coronavirus pneumonia (COVID-19) implicate special control measures. J Med Virol. 2020 Jun. 92 (6): 568-576. DOI: 10.1002/jmv. 25748 .

[5] Di Filippo L, Formenti AM, Rovere-Querini P, Carlucci M, Conte C, Ciceri F, et al. Hypocalcemia is highly prevalent and predicts hospitalization in patients with COVID-19. Endocrine. 2020 Jun; 68 (3): 475-478. doi: 10.1007/s12020020-02383-5.

[6] Di Filippo L, Formenti AM, Doga M, Frara S, Rovere-Querini P, Bosi E, Carlucci M, Giustina A. Hypocalcemia is a distinctive biochemical feature of hospitalized COVID-19 patients. Endocrine. 2020 Dec; 71 (1): 1-5. doi: 10.1007/s12020-020-02541-9.

[7] Singh VP, Khatua B, El-Kurdi B, Rood C. Mechanistic basis and therapeutic relevance of hypocalcemia during severe COVID-19 infection. Endocrine. 2020 Oct 24: 1-2. doi: 10.1007/s12020-020-02530-y.

[8] Mousseaux C, Dupont A, Rafat C, Ekpe K, Ghrenassia E, Kerhuel L, et al. Epidemiology, clinical features, and management of severe hypercalcemia in experimental group patients. Ann Intensive Care. 2019; 9 (1): 133. doi: 10.1186/s13613-019-0606-8.

[9] Guan WJ, Ni ZY, Hu Y, Liang W, Ou C. He J, et al. Clinical characteristics of coronavirus disease 2019 in China. N. Engl. J. Med. 2020; 382 (18): 1708-1720. doi: 10.1056/NEJMoa2002032. 
[10] Millet JK, Whittaker GR. Physiological and molecular triggers for SARS-CoV membrane fusion and entry into host cells. Virology. 2018; 517: 3-8. doi: 10.1016/j.virol.2017.12.015.

[11] Straus MR, Tang T, Lai AL, Flegel A, Bidon M, Freed JH, Daniel S, Whittaker GR. Ca2+ Ions Promote Fusion of Middle East Respiratory Syndrome Coronavirus with Host Cells and Increase Infectivity. J Virol. 2020 Jun 16; 94 (13): e00426-20. doi: 10.1128/JVI.00426-20. PMID: 32295925; PMCID: PMC7307142.

[12] Nathan L, Lai AL, Millet JK, Straus MR, Freed JH, Whittaker GR, et al. Calcium ions directly interact with the Ebola virus fusion peptide to promote structure-function changes that enhance infection. ACS Infect. Dis. 2020; 6 (2): 250-260. doi: 10.1021/acsinfecdis.9b00296.

[13] Bossoni S., Chiesa L., Giustina A. Severe hypocalcemia in a thyroidectomized woman with Covid-19 infection. Endocrine. 2020; 68: 253-254. Doi: 10.1007/s12020-020-02326-0.

[14] General Office of the National Health Commission, Office of the State Administration of Traditional Chinese Medicine. "Diagnosis and Treatment Plan for Pneumonia from Novel Coronavirus Infection (Trial Version 7)" National Health Office Medical Letter No. 184. 2020. Available at: http://www.nhc.gov.cn/yzygj/s7652m/202003/a31191442e294 74b98bfed5579d5af95.shtml.

[15] Guidelines for Diagnosis and Treatment of Hypocalcemia. Chinese Medical Association Osteoporosis and Bone Mineral Disease Branch. Chinese Medical Association Fourth National Osteoporosis and Bone Mineral Disease Academic Conference Paper Collection. Chinese Medical Association Osteoporosis and Bone Mineral Salt Disease Branch: Chinese Medical Association, 2006: 32-34.

[16] Booth CM, Matukas LM, Tomlinson GA, Rachlis AR, Rose DB, Dwosh HA, et al. Clinical features and short-term outcomes of 144 patients with SARS in the greater Toronto area [published correction appears in JAMA. JAMA, 2003; 289 (21): 2801-2809. DOI: 10.1001/jama.289.21.JOC30885.

[17] He Qing, Zheng Baozhong, Pang Chongjie, Dai Chenlin, Gong Lu, Qiu Mingcai et al. Hypocalcemia in SARS patients. Chinese Journal of Endocrinology and Metabolism. 2004. (1): 11-12. doi: 10.3760/j.issn:1000-6699.2004.01.005.

[18] Akirov A, Gorshtein A, Shraga-Slutzky I, Shimon I. Calcium levels on admission and before discharge are associated with mortality risk in hospitalized patients. Endocrine. 2017; 57 (2): 344-351. doi: 10.1007/s12020-017-1353-y.

[19] Aberegg SK. Ionized Calcium in the ICU: Should It Be Measured and Corrected? Chest. 2016; 149 (3): 846-55. doi: 10.1016/j.chest.2015.12.001.

[20] Channappanavar R, Fett C, Mack M, Eyck PPT, Meyerholz DK. Perlman S. Sex-Based Differences in Susceptibility to Severe Acute Respiratory Syndrome Coronavirus Infection. J
Immunol. 2017; $198 \quad$ (10): 4046-4053 $\quad$ doi: 10.4049/jimmunol.1601896.

[21] Sanaie S, Mahmoodpoor A, Hamishehkar H, Shadvar K, Salimi N, Montazer M, Iranpour A, Faramarzi E. Association Between Disease Severity and Calcium Concentration in Critically Ill Patients Admitted to Intensive Care Unit. Anesth Pain Med. 2018 Feb 24; 8 (1): e57583. doi: 10.5812/aapm.57583.

[22] Wang Wenyue. The effect of different nutritional support methods on the incidence of adverse complications in experimental group patients. International Journal of Nursing, 2014, 0 (4): 863-864. doi: 10.3760/cma.j.issn.16734351.2014.04.069.

[23] Giustina A, Formenti AM. Preventing a covid-19 pandemic can high prevalence of severe hypovitaminosis D play a role in the high impact of Covid infection in Italy? BMJ. 2020; 368: $\mathrm{m} 810$.

[24] Thomas T, Stefanoni D, Reisz JA, Nemkov T, Bertolone L, Francis RO et al. COVID-19 infection alters kynurenine and fatty acid metabolism, correlating with IL-6 levels and renal status. JCI Insight. 2020. 5 (14): e140327. Doi: 10.1172/jci.insight.140327.

[25] Frank H. Lau FH, Rinku M, Radbeh T, Fouad S, Ryan H, et al. Vitamin D Insufficiency is Prevalent in Severe COVID19.medRxiv. 2020. Doi: 10.1101/2020.04.24.20075838.

[26] Maggini S, Wintergerst ES, Beveridge S, Hornig DH. Selected vitamins and trace elements support immune function by strengthening epithelial barriers and cellular and humoral immune responses. Br J Nutr, 2007, 98, Suppl 1: S29-S35. DOI: $10.1017 /$ S0007114507832971.

[27] Wong CK, Lam CW, Wu AK, Ip KW, Lee NS, Chan IS, et al. Plasma inflammatory cytokines and chemokines in severe acute respiratory syndrome. Clin Exp Immunol. 2004; 136 (1): 95-103. DOI: 10.1111/j.1365-2249.2004.02415.x.

[28] Mahallawi WH, Khabour OF, Zhang Q, Makhdoum HM, Suliman BA. MERS-CoV infection in humans is associated with a pro-inflammatory Th1 and Th17 cytokine profile. Cytokine. 2018. 201; 104: 8-13. DOI: 10.1016/j.cyto.2018.01.025.

[29] Schardey J, Globig AM, Janssen C, Hofmann M, Manegold P, Thimme R. et al. Vitamin D Inhibits Pro-Inflammatory T the Cell Function in Patients With Inflammatory Bowel Disease [J]. J Crohns Colitis. 2019; 13 (12): 1546-1557. The DOI: 10.1093/ecco-jcc/jjz090.

[30] Evans MA, Kim the HA, Ling YH, Uong S, Vinh A, De Silva TM, et al. Vitamin D3 Reduces Supplementation Subsequent Brain Ischemic Injury and Inflammation the Associated with the Stroke. Neuromolecular Med. 2018; 20 (1): 147-159. DOI: 10.1007/s12017-018 -8484-Z. 